\title{
Controlled Reduction of Graphene Oxide Using Sulfuric Acid
}

\author{
Ana Cecilia Reynosa-Martínez ${ }^{1}$ (D), Erika Gómez-Chayres ${ }^{1}$, Rafael Villaurrutia ${ }^{2}$ and Eddie López-Honorato ${ }^{1,3, * \mathbb{D}}$ \\ 1 Centro de Investigación y de Estudios Avanzados del IPN, Unidad Saltillo, Av. Industria Metalúrgica 1062, \\ Parque Industrial, Ramos Arizpe 25900, Coahuila, Mexico; cecilia.reynosa@cinvestav.edu.mx (A.C.R.-M.); \\ erika.chayres@cinvestav.mx (E.G.-C.) \\ 2 Thermo Fisher Scientific de México, Avenida Morones Prieto 2805 Pte., Monterrey 64710, \\ Nuevo León, Mexico; rafael.arenas@thermofisher.com \\ 3 Oak Ridge National Laboratory, Oak Ridge, TN 37831, USA \\ * Correspondence: honoratole@ornl.gov
}

Citation: Reynosa-Martínez, A.C.; Gómez-Chayres, E.; Villaurrutia, R.; López-Honorato, E. Controlled Reduction of Graphene Oxide Using Sulfuric Acid. Materials 2021, 14, 59. https: / / dx.doi.org/10.3390/ma14 010059

\section{Received: 28 October 2020}

Accepted: 18 December 2020

Published: 25 December 2020

Publisher's Note: MDPI stays neutral with regard to jurisdictional claims in published maps and institutional affiliations.

Copyright: () 2020 by the authors. Licensee MDPI, Basel, Switzerland. This article is an open access article distributed under the terms and conditions of the Creative Commons Attribution (CC BY) license (https: / / creativecommons.org/ licenses/by/4.0/).

\begin{abstract}
Sulfuric acid under different concentrations and with the addition of $\mathrm{SO}_{3}$ (fuming sulfuric acid) was studied as a reducing agent for the production of reduced graphene oxide (RGO). Three concentrations of sulfuric acid $(1.5,5$, and $12 \mathrm{M})$, as well as $12 \mathrm{M}$ with $30 \% \mathrm{SO}_{3}$, were used. The reduction of graphene oxide increased with $\mathrm{H}_{2} \mathrm{SO}_{4}$ concentration as observed by Fourier-transformed infrared spectroscopy and X-ray photoelectron spectroscopy. It was observed that GO lost primarily epoxide functional groups from 40.4 to $9.7 \%$ and obtaining $69.8 \%$ carbon when using $12 \mathrm{M} \mathrm{H}_{2} \mathrm{SO}_{4}$, without leaving sulfur doping. Additionally, the appearance of hexagonal domain structures observed in transmission electron microscopy and analyzed by selected area electron diffraction patterns confirmed the improvement in graphitization. Although the addition of $\mathrm{SO}_{3}$ in $\mathrm{H}_{2} \mathrm{SO}_{4}$ improved the GO reduction with $74 \%$ carbon, as measured by XPS, the use of $\mathrm{SO}_{3}$ introduced sulfur doping of $1.3 \%$. RGO produced with sulfuric acid was compared with a sample obtained via ultraviolet (UV) irradiation, a very common reduction route, by observing that the RGO produced with sulfuric acid had a higher $\mathrm{C} / \mathrm{O}$ ratio than the material reduced by UV irradiation. This work showed that sulfuric acid can be used as a single-step reducing agent for RGO without sulfur contamination.
\end{abstract}

Keywords: reduce graphene oxide; sulfuric acid; fuming sulfuric acid; UV-radiation

\section{Introduction}

Graphene is a 2D C nanomaterial with $s p^{2}$ hybridization that has a wide range of industrial applications, including the production of ion-selective graphene oxide (GO) membranes for desalination and salinity gradient energy, radioactive wastewater treatment, the production of heavy water, and others [1-4]. Generally, this material is used as graphene nanoplatelets (GNPs) due to the possibility of producing it directly from graphite in larger volumes at a lower cost. For example, it can be produced from mechanical exfoliation by using attrition milling [5-7] or from the oxidation, exfoliation (GO), and reduction (reduced GO [RGO]) of graphite [8-12]. Although GO reduction is a suitable route for the mass production of graphene, the restoration of the graphene lattice by eliminating the O functional groups with chemical treatments or ultraviolet (UV) light results in GNPs with structural defects and different concentrations of $\mathrm{O}$, depending on the processing route. For example, hydrazine leaves a $\mathrm{N}$ doping that is difficult to remove from the final product $[9,10]$, whereas the reduction that uses UV light can cause graphene sheet fragmentation [13]. Therefore, it is desirable to find simple and cost-effective routes to produce RGO.

Sulfur-containing compounds were also previously suggested as reducing agents for RGO production. S-containing compounds such as sodium hydrogen sulfite $\left(\mathrm{NaHSO}_{3}\right)$, sodium sulfide nonahydrate $\left(\mathrm{Na}_{2} \mathrm{~S} \cdot 9 \mathrm{H}_{2} \mathrm{O}\right)$, sodium thiosulfate $\left(\mathrm{Na}_{2} \mathrm{~S}_{2} \mathrm{O}_{3}\right)$, and thionyl chloride $\left(\mathrm{SOCl}_{2}\right)$, have been used for the reduction of $\mathrm{GO}$. These compounds were able to decrease the concentration of hydroxyl and epoxide groups since the mass percentage of 
oxygen decreased from 50.5 to $15.3 \%$ with $\mathrm{NaHSO}_{3}, 18.6 \%$ with $\mathrm{Na}_{2} \mathrm{~S}, 25 \%$ with $\mathrm{Na}_{2} \mathrm{~S}_{2} \mathrm{O}_{3}$, and $13.4 \%$ with $\mathrm{SOCl}_{2}$ [10]. However, their use also resulted in the presence of sulfur with values from 0.79 to 1.98 mass\% [10]. Other methods of chemical reduction of GO involved two-step processes such as diluted and concentrated $\mathrm{H}_{2} \mathrm{SO}_{4}$, as well as $\mathrm{H}_{2} \mathrm{SO}_{4}$ and sodium borohydride $\left(\mathrm{NaBH}_{4}\right)$ [8]. In these studies, the proportion of epoxide and hydroxyl groups decreased from 36 to $12 \%$ with concentrated $\mathrm{H}_{2} \mathrm{SO}_{4}$ and until $9 \%$ with $\mathrm{H}_{2} \mathrm{SO}_{4}$ and $\mathrm{NaBH}_{4}$ [8]. Dilute sulfuric acid has been used to open the epoxy ring and transform it into hydroxyl groups, to later remove them with concentrated sulfuric acid at $120{ }^{\circ} \mathrm{C}$ [8]. In order to find a more eco-friendly method, $\mathrm{H}_{2} \mathrm{SO}_{4}$ has been combined with organic solvents such as dimethyl sulfoxide (DMSO) and $\mathrm{N}, \mathrm{N}^{\prime}$-dimethylformamide (DMF), also in a two-step process. It was possible to increase the carbon percentage from $50.6 \%$ to 80.8 and $84.5 \%$ with DMF and DMSO, respectively. The C/O ratio was also increased from $1.4 \%$ to $6.7 \%$ for DMF and $8.0 \%$ for DMSO. However, as in most chemical reduction methods, DMF resulted in nitrogen contamination of $1.5 \%$ and DMSO with $0.6 \%$ of sulfur [14].

Therefore, to simplify the reduction process, the authors studied the effects of $\mathrm{H}_{2} \mathrm{SO}_{4}$ concentration and $\mathrm{H}_{2} \mathrm{SO}_{4}$ with $30 \%$ of sulfur trioxide $\left(\mathrm{SO}_{3}\right)$, commonly known as fuming sulfuric acid, for the reduction of $\mathrm{GO}$ in a single-step process. Reduction was observed to strongly depend on $\mathrm{H}_{2} \mathrm{SO}_{4}$ concentration since, at $12 \mathrm{M}$, the graphene structure was reestablished due to the loss of functional groups, such as epoxide, showing that $12 \mathrm{M}$ $\mathrm{H}_{2} \mathrm{SO}_{4}$ can be used to reduce $\mathrm{GO}$ without the need for a preliminary step using diluted $\mathrm{H}_{2} \mathrm{SO}_{4}$ as previously reported. However, the results show that adding $\mathrm{SO}_{3}$ into $\mathrm{H}_{2} \mathrm{SO}_{4}$ not only slightly improved the reduction of graphene oxide, it also resulted in the doping of the final product with 1.3 at $\%$ sulfur.

\section{Experimental Section}

\subsection{Synthesis of $G O$ and $R G O$}

GO was prepared by using the improved Hummers method proposed by Marcano et al. [15]. A mixture of sulfuric acid (95-98\%, Sigma-Aldrich, St. Louis, MO, USA) and phosphoric acid (85.8\%, J. T. Beaker Phillipsburg, NJ, USA) with a 9:1 volume ratio was prepared with the addition of $3 \mathrm{~g}$ of graphite flakes (95\%, Sigma-Aldrich St. Louis, MO, USA). This mixture was stirred for $30 \mathrm{~min}$ before adding $6 \mathrm{~g}$ of potassium permanganate $\left(99 \%\right.$, Sigma-Aldrich St. Louis, MO, USA) at a temperature of $50{ }^{\circ} \mathrm{C}$. After $24 \mathrm{~h}$, the temperature of the mixture dropped to $2{ }^{\circ} \mathrm{C}$, and $3 \mathrm{~mL}$ of hydrogen peroxide (30\%, Sigma-Aldrich St. Louis, MO, USA) were carefully added. Subsequently, deionized water was added until a $\mathrm{pH}$ of 1 was reached. The solid material was washed twice with a solution of $\mathrm{HCl}$ at 30\% v/v (36.5-38\% Sigma-Aldrich St. Louis, MO, USA), deionized water, and finally ethanol (99.5\%, Analytyka Mexico State, Mexico). The sample was coagulated by using ethyl ether (99\%, Sigma-Aldrich St. Louis, MO, USA) and centrifuged for $30 \mathrm{~min}$ at 3500 RPM (XC-2450 PREMIERE). The solid was then dispersed in ethanol (99.5\%, Analytyka Mexico State, Mexico) with an ultrasonic bath (Branson $380040 \mathrm{kHz} / 230-240 \mathrm{~V}$ Danbury, CT, USA) for $1 \mathrm{~h}$ to exfoliate the material. The final GO was then dried at $80^{\circ} \mathrm{C}$ for $12 \mathrm{~h}$ and milled before its characterization [16]. The $\mathrm{pH}$ of a suspension of GO in deionized water generally is between 2 and 3; measured using an OHAUS potentiometer, model starter 2100 (Parsippany, NJ, USA).

RGO was obtained by mixing $0.3 \mathrm{~g}$ of GO in a balloon flask with $50 \mathrm{~mL}$ of $\mathrm{H}_{2} \mathrm{SO}_{4}$ ( $\geq 97.5 \%$, Sigma-Aldrich St. Louis, MO, USA) at $1.5,5$, and $12 \mathrm{M}$, in addition to a $12 \mathrm{M}$ $\mathrm{H}_{2} \mathrm{SO}_{4}$ with $30 \%$ of sulfur trioxide $\left(\mathrm{SO}_{3}\right)$ (as received fuming sulfuric acid, Sigma-Aldrich, $28-32 \%$ St. Louis, MO, USA), and kept under reflux at $90{ }^{\circ} \mathrm{C}$ for $24 \mathrm{~h}$. Afterward, RGO was separated by using a centrifuge (PREMIERE XC-2450) at 3500 RPM for $15 \mathrm{~min}$. The solid was washed several times with deionized water until a $\mathrm{pH}$ of 6 was reached. Finally, the solid was dried at $80^{\circ} \mathrm{C}$ for $12 \mathrm{~h}$ and milled in an agate mortar. For comparison purposes, RGO was also prepared by using a UV reduction process in water with three UV lamps of $7.2 \mathrm{~W}$ (Tecno Lite, F8T5BLB) with a wavelength of $368 \mathrm{~nm}$. The highest irradiance inside 
the box was measured at $74 \mu \mathrm{W} / \mathrm{cm}^{2}$ with a photodiode OPHIR, DP-300 series (Jerusalem, Israel). The GO suspensions were prepared in borosilicate glass flasks by using $12.5 \mathrm{mg}$ of $\mathrm{GO}$ in $10 \mathrm{~mL}$ of deionized water. The $\mathrm{pH}$ was adjusted to 7 with $\mathrm{HCl}$ or $\mathrm{NaOH}$ solutions, as necessary. The suspensions were then placed into the black box container with constant stirring for $120 \mathrm{~h}$. To avoid water evaporation, the temperature was kept at $25^{\circ} \mathrm{C}$ by using a recirculating chiller (IKA RC 5 basic Staufen, Germany) [13].

\subsection{Characterization}

The functional groups and C content of GO and RGO were characterized by Fouriertransform infrared spectroscopy (FTIR) (PerkinElmer Frontier FTIR/NIR, Waltham, MA, USA) and by X-ray photoelectron spectroscopy (XPS) (PHI VersaProbe II, Chanhassen, MN, USA) with a $2 \times 10^{-8}$ mTorr vacuum chamber, an $\mathrm{Al}$ anode as an $\mathrm{X}$-ray monochromatic source with radiation energy of $1486.6 \mathrm{eV}$, and an analysis range from 1400 to $0 \mathrm{eV}$. The processing of the XPS data of the C1s region was carried out in the CasaXPS program using a Shirley background [17]. Carbon with $s p^{2}$ and $s p^{3}$ hybridization $(C-C / C=C)$ was assigned to the binding energy of $284.9 \mathrm{eV}$ and adjusted with a Gaussian function with $30 \%$ of a Lorentzian function with symmetric shape. The signals corresponding to the oxygenated functional groups were assigned to $285.9 \mathrm{eV}(\mathrm{C}-\mathrm{OH}), 286.9 \mathrm{eV}(\mathrm{C}-\mathrm{O}-\mathrm{C}), 288.2 \mathrm{eV}(\mathrm{C}=\mathrm{O})$, and $289.3 \mathrm{eV}(\mathrm{COOH})$ [12,18-21] which were also fitted with a Gaussian with $30 \%$ Lorentzian function and with symmetric shape, whereas the binding energy was calibrated using the carbon energy at $284 \mathrm{eV}$ [17]. The microstructure and elemental analyses were also characterized by an Aberration corrected FEI TITAN (Hillsboro, OR, USA) transmission electron microscope (TEM) operated at $300 \mathrm{kV}$. Raman spectroscopy was also performed by using a RENISHAW (Wotton-under-Edge, Gloucestershire, UK) inVia Microscope with a laser excitation wavelength of $514 \mathrm{~nm}$ and a $50 \times$ lens. The Fityk program and a mixture of Gaussian (G, D2, and D3 bands) and Lorentzian (D, D4, and C bands) functions were used to fit the Raman bands [22].

\section{Results and Discussion}

Figure 1 shows the FTIR spectra of the as-produced GO and the RGO treated with $\mathrm{H}_{2} \mathrm{SO}_{4}$ and fuming $\mathrm{H}_{2} \mathrm{SO}_{4}$. The $\mathrm{GO}$ spectrum (Figure $1 \mathrm{a}$ ) showed a broad and intense band close to $3500 \mathrm{~cm}^{-1}$ that corresponds to the stretching mode of the hydroxyl $(-\mathrm{OH})$ functional group, whereas the signal at $1725 \mathrm{~cm}^{-1}$ was associated with the carbonyl group $(\mathrm{C}=\mathrm{O})$. Similarly, the signal at $1600 \mathrm{~cm}^{-1}$ was assigned to the presence of carbon with $s p^{2}$ hybridization, whereas the band at $1500 \mathrm{~cm}^{-1}$ corresponds to carbon with $s p^{3}$ hybridization, resulting from the double bond breaking of graphite. Finally, two bands around 1040 and $1200 \mathrm{~cm}^{-1}$ were observed corresponding to $\mathrm{C}-\mathrm{O}$ bonds assigned to the hydroxyl $(\mathrm{C}-\mathrm{OH})$ and epoxide (C-O-C) groups, respectively [23].

Once $\mathrm{GO}$ was treated with $\mathrm{H}_{2} \mathrm{SO}_{4}$, the intensity of all the bands gradually decreased with $\mathrm{H}_{2} \mathrm{SO}_{4}$ concentration. The most evident decrease in intensity was observed after the chemical treatment with $12 \mathrm{M} \mathrm{H}_{2} \mathrm{SO}_{4}$ and fuming $\mathrm{H}_{2} \mathrm{SO}_{4}$ (Figure $1 \mathrm{~d}, \mathrm{e}$ ); at this concentration, for example, the band at $3500 \mathrm{~cm}^{-1}$ disappeared. This behavior is associated with the loss of the GO functional groups since pure $\mathrm{C}$ is not infrared active [24]. Conversely, although the RGO obtained by UV irradiation also showed a reduction in band intensity, after $120 \mathrm{~h}$ under UV irradiation, it was still possible to identify the presence of $\mathrm{C}-\mathrm{OH}, \mathrm{C}=\mathrm{O}, \mathrm{C}-\mathrm{O}-\mathrm{C}$, and $\mathrm{COOH}$ functional groups, obtaining only similar results as RGO treated with $1.5 \mathrm{M}$ $\mathrm{H}_{2} \mathrm{SO}_{4}$. 


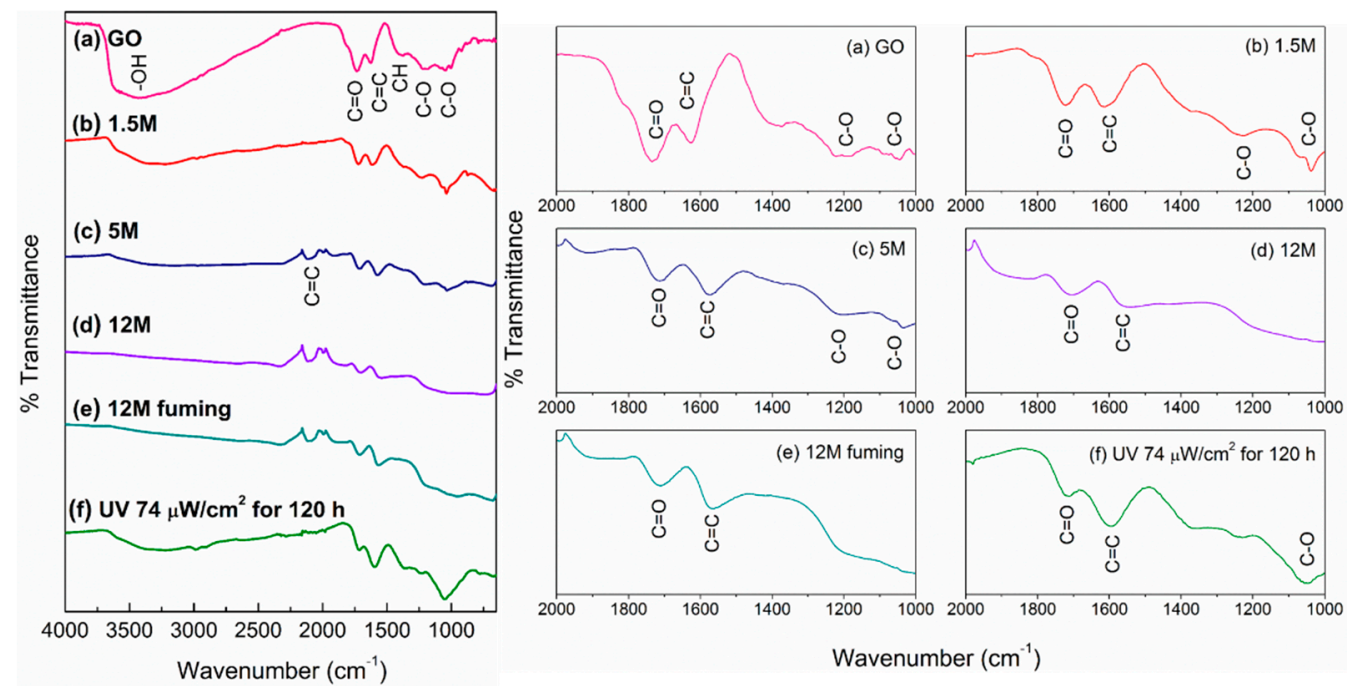

Figure 1. Infrared spectra (left) and details of the IR spectra from 2000 to $1000 \mathrm{~cm}^{-1}$ (right) of (a) as-produced GO and RGO with $\mathrm{H}_{2} \mathrm{SO}_{4}$ at (b) $1.5 \mathrm{M}$, (c) $5 \mathrm{M}$, (d) $12 \mathrm{M}$, (e) fuming $\mathrm{H}_{2} \mathrm{SO}_{4} 12 \mathrm{M}$, and (f) RGO irradiated at $74 \mu \mathrm{W} / \mathrm{cm}^{2}$ for $120 \mathrm{~h}$.

Figure 2 shows the XPS spectra of all the RGO produced. In the deconvoluted spectrum of as-produced GO (Figure 2a), it was possible to identify the bands at $284.9 \pm 0.2 \mathrm{eV}$ which correspond to the $C$ structure with $s p^{2}$ and $s p^{3}$ hybridization [12,19-21]. Furthermore, the signals corresponding to $\mathrm{C}-\mathrm{OH}(286.0 \pm 0.1 \mathrm{eV}), \mathrm{C}-\mathrm{O}-\mathrm{C}(287.1 \pm 0.2 \mathrm{eV})$, $\mathrm{C}=\mathrm{O}(288.2 \pm 0.05 \mathrm{eV})$, and $\mathrm{COOH}(289.2 \pm 0.1 \mathrm{eV})$ were also identified [18]. Similar to FTIR, it was observed that the intensity of the bands that correspond to the oxygenated functional groups decreased with $\mathrm{H}_{2} \mathrm{SO}_{4}$ concentration (Figure $2 \mathrm{~b}-\mathrm{e}$ ). The $\mathrm{C}-\mathrm{O}-\mathrm{C}$ group reduced its concentration gradually from $40.4 \%$ in as-produced GO to $9.7 \%$ in RGO with $12 \mathrm{M} \mathrm{H}_{2} \mathrm{SO}_{4}$ (Table 1). On the other hand, the $\mathrm{C}-\mathrm{OH}$ group increased its percentage from 4.3 to $5.5 \%$ after been treated with $1.5 \mathrm{M} \mathrm{H}_{2} \mathrm{SO}_{4}$ but decreased to $1.9 \%$ with a $5 \mathrm{M}$ treatment. Similar behavior was observed for the $\mathrm{C}=\mathrm{O}$ and $\mathrm{COOH}$ functional groups, which increased from 9.6 and $2.3 \%$ to 16.4 and $3.7 \%$, respectively, with $1.5 \mathrm{H}_{2} \mathrm{SO}_{4}$, and decreased to 9.0 and $3.6 \%$ with $5 \mathrm{M} \mathrm{H}_{2} \mathrm{SO}_{4}$. Nevertheless, $\mathrm{C}=\mathrm{O}$ decreased again to $1.8 \%$ and $\mathrm{COOH}$ remained at $3.6 \%$ after been treated with $12 \mathrm{M} \mathrm{H}_{2} \mathrm{SO}_{4}$. All these changes in the concentration of oxygenated functional groups were reflected in the $\mathrm{GO}$ carbon structure since the as-produced GO had $43.3 \%$ of $C-C / C=C$ due to its high oxidation degree due to the use of a high concentration of oxidating agent $\left(\mathrm{KMnO}_{3}\right)$ [16]; however, this value changed to $69.8 \%$ after treatment with $12 \mathrm{M} \mathrm{H}_{2} \mathrm{SO}_{4}$. Previously, Kim et al. [8] reported GO reduction by using $\mathrm{H}_{2} \mathrm{SO}_{4}$ and $\mathrm{NaBH}_{4}$ as an initial step. An increase of $\mathrm{C}=\mathrm{C} / \mathrm{C}-\mathrm{C}$ bonds from 43 to $69 \%$ was reported from the loss of oxygenated functional groups that were similar values to this work, showing that the single use of $\mathrm{H}_{2} \mathrm{SO}_{4}$ can increase $\mathrm{C}$ content from 56.1 to 79.9 at $\%$ (Table 1). Furthermore, some authors have reported that the $\mathrm{NaBH}_{4}$ compound might destroy the graphene-like structure that, in addition to $\mathrm{N}$ doping, generates unfavorable effects on graphene conduction and flexibility [12]. In this case, even when fuming $\mathrm{H}_{2} \mathrm{SO}_{4}$ increased the $\mathrm{C}-\mathrm{C} / \mathrm{C}=\mathrm{C}$ content to $74 \%$ and decreased the functional groups $\mathrm{C}-\mathrm{O}-\mathrm{C}, \mathrm{C}=\mathrm{O}$, and $\mathrm{COOH}$ to $2.9,7.5$, and $2.2 \%$, respectively, the presence of $\mathrm{S}$ was observed in 1.3 at $\%$. Conversely, none of the samples produced with only $\mathrm{H}_{2} \mathrm{SO}_{4}$ showed the presence of sulfur contamination (Figure S1).

On the other hand, the RGO obtained by UV irradiation (Figure 2f) also showed an increase in the $s p^{2}$ and $s p^{3}$ hybridization band from 43.3 to $61.4 \%$ and a decrease in the bands that correspond to oxygenated functional groups, primarily the band that corresponds to C-O-C but not at the same level as $\mathrm{GO}$ treated with $12 \mathrm{M} \mathrm{H}_{2} \mathrm{SO}_{4}$. The C-O-C decreased its concentration from 40.4 to $22.9 \%$ in as-produced GO and irradiated RGO, respectively. Additionally, $\mathrm{C}-\mathrm{OH}$ increased its concentration from 4.3 to $6 \%$ in as-produced and irradiated GO, respectively. Furthermore, $\mathrm{C}=\mathrm{O}$ and $\mathrm{COOH}$ groups maintain their 
concentration in values around 8.6 and $1.1 \%$ These variations in composition were also reflected on the $\mathrm{C} / \mathrm{O}$ ratios measured for each sample (Table 1) since the value increased from 1.4 to 4 for $\mathrm{H}_{2} \mathrm{SO}_{4} 12 \mathrm{M}$ after losing $\sim 50 \%$ of the original $\mathrm{O}$ present in $\mathrm{GO}$, whereas the RGO obtained with UV light only reached a value of $2.2 \mathrm{C} / \mathrm{O}$ with a loss of $\sim 30 \% \mathrm{O}$.
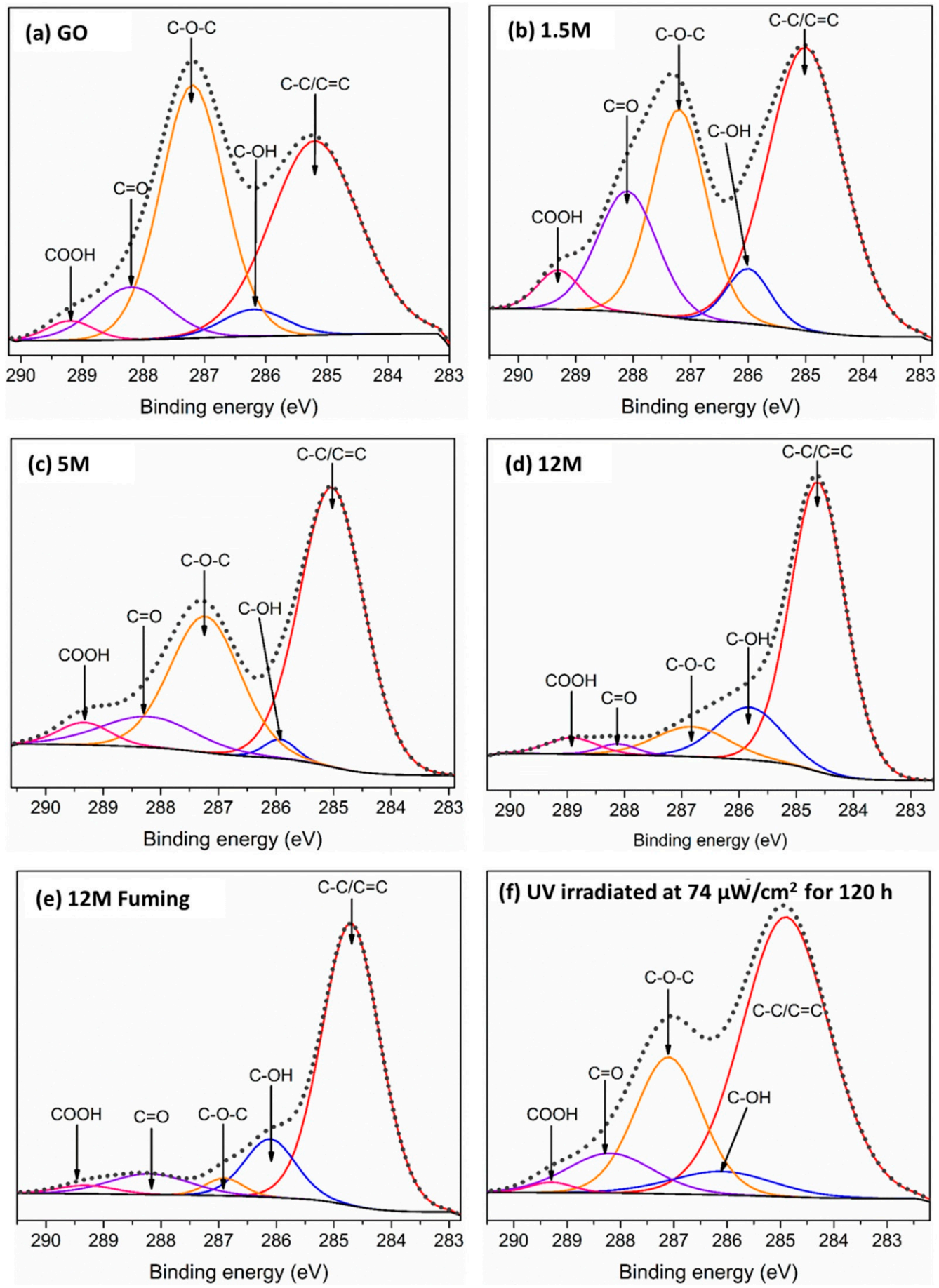

Figure 2. XPS spectra of (a) as-produced GO and RGO with $\mathrm{H}_{2} \mathrm{SO}_{4}$ in (b) $1.5 \mathrm{M}$, (c) $5 \mathrm{M}$, and (d) $12 \mathrm{M}$ concentrations; (e) RGO with fuming $\mathrm{H}_{2} \mathrm{SO}_{4}$ in $12 \mathrm{M}$ concentration; and (f) RGO irradiated at $74 \mu \mathrm{W} / \mathrm{cm}^{2}$ for $120 \mathrm{~h}$. 
Table 1. Quantification of functional groups in as-produced $\mathrm{GO}$ and $\mathrm{RGO}$ with $\mathrm{H}_{2} \mathrm{SO}_{4}$ and fuming $\mathrm{H}_{2} \mathrm{SO}_{4}$ by XPS.

\begin{tabular}{ccccccc}
\hline \multirow{2}{*}{ Bond } & GO & $\mathbf{1 . 5} \mathbf{M}$ & $\mathbf{5 ~ M}$ & $\mathbf{1 2} \mathbf{M}$ & Fuming $\mathbf{1 2} \mathbf{M}$ & $\mathbf{7 4} \boldsymbol{\mu W} / \mathbf{c m}^{\mathbf{2}} \mathbf{1 2 0} \mathbf{~}$ \\
\cline { 2 - 7 } & $\mathbf{\%}$ & $\mathbf{\%}$ & $\mathbf{\%}$ & $\mathbf{\%}$ & $\mathbf{\%}$ & $\mathbf{\%}$ \\
\hline C-C/C=C & 43.3 & 48.6 & 55.8 & 69.8 & 74 & 61.4 \\
C-OH & 4.3 & 5.5 & 1.9 & 15.1 & 13.4 & 6 \\
C-O-C & 40.4 & 25.2 & 29.7 & 9.7 & 2.9 & 22.9 \\
C=O & 9.6 & 16.4 & 9.0 & 1.8 & 7.5 & 8.6 \\
COOH & 2.3 & 3.7 & 3.6 & 3.6 & 2.2 & 1.1 \\
\hline Carbon At. \% & 56.1 & 70.1 & 71.9 & 79.9 & 77.8 & 64.9 \\
Oxygen At. \% & 41.3 & 29.9 & 28.1 & 20.1 & 20.9 & 29.8 \\
\hline C/O & 1.4 & 2.3 & 2.6 & 4.0 & 3.7 & 2.2 \\
\hline
\end{tabular}

The microstructure of GO and RGO is shown in Figure 3. Figure 3a shows the asproduced GO layer that is $\sim 20 \mu \mathrm{m}$ long and has the appearance of wrinkles generated due to the tension in the network created by the presence of oxygenated functional groups [25]. The disorder in the GO C structure was evident from the formation of concentric rings in its selected area electron diffraction pattern (SAEDP) [26]. This microstructure changed after treatment with $12 \mathrm{M} \mathrm{H}_{2} \mathrm{SO}_{4}$, as observed in Figure $3 b$,c. Figure $3 \mathrm{~b}$ shows the bright field of the hexagonal crystalline structure taken in a zone axis orientation, as shown in the SAEDP attached. The main importance of this image is remarked on in Figure $3 \mathrm{c}$ in which a dark field image of the same area shows the differentiated hexagonal domain structures obtained with the conical dark field technique, which allows images to be obtained from the entire set of intensities in the diffraction pattern. The RGO appeared to be formed of $\sim 5 \mu \mathrm{m}$ particles. Dark field images showed the formation of areas with more crystalline structure since the bright areas in the dark field correspond to the settlement of the $\mathrm{C}$ domains in the same direction. Furthermore, the SAED pattern shows a hexagonal diffraction pattern that confirms the restructuring of graphene and the formation of areas with good crystallinity [27].

The Raman spectra of GO and RGO are shown in Figure 4 and Figure S2. The Raman spectrum of as-produced GO in Figure 4a shows the presence of the $G$ band in $1591.93 \mathrm{~cm}^{-1}$ generated by the stretching of $s p^{2}$ bonds from an ideal graphite lattice associated with the first-order Raman mode $\mathrm{E}_{2 \mathrm{~g}}$. It was also observed that the $\mathrm{D}$ band in $1356.04 \mathrm{~cm}^{-1}$, which is attributed to a disordered graphitic lattice due to the conversion of $s p^{2}$ to $s p^{3}$, bonds by the graphene oxidation, which is associated with the vibrational mode $\mathrm{A}_{1 \mathrm{~g}}[28,29]$ (Table S1). Three more bands were also identified as D2 at $\sim 1620 \mathrm{~cm}^{-1}$, D3 at $1500 \mathrm{~cm}^{-1}$, and D4 at $\sim 1200 \mathrm{~cm}^{-1}$ (Table S2) [28], which are related to the disorder in the basal plane and the presence of amorphous $C[28,30,31]$. Additionally, the $C$ band close to $1700 \mathrm{~cm}^{-1}$, which is generally attributed to the presence of $\mathrm{C}=\mathrm{O}$ functional groups, was also identified [22]. The $\mathrm{G}$ and $\mathrm{D}$ bands were also observed in the RGO spectra treated with $12 \mathrm{M} \mathrm{H}_{2} \mathrm{SO}_{4}$; however, their position shifted to $1599.28 \mathrm{~cm}^{-1}$ for the $\mathrm{G}$ band and $1357.97 \mathrm{~cm}^{-1}$ for the $\mathrm{D}$ band (Table S1). Additionally, for the UV irradiated RGO, the G and D bands shifted to 1593.78 and $1357.03 \mathrm{~cm}^{-1}$, respectively. The shift of the $G$ band towards the position found in graphite of approximately $1581 \mathrm{~cm}^{-1}$ [9] is generally indicative of the restoration of the $s p^{2}$ structure in carbon [32]. However, our results show that the G bands in RGO sifted towards higher wavenumbers. Schüpfer et al. observed similar behavior when studying the transition from $s p^{3}$ to $s p^{2}$ hybridization in heat-treated graphitic and non-graphitic carbon, with a $\mathrm{G}$ band close to $1600 \mathrm{~cm}^{-1}$ [33]. 


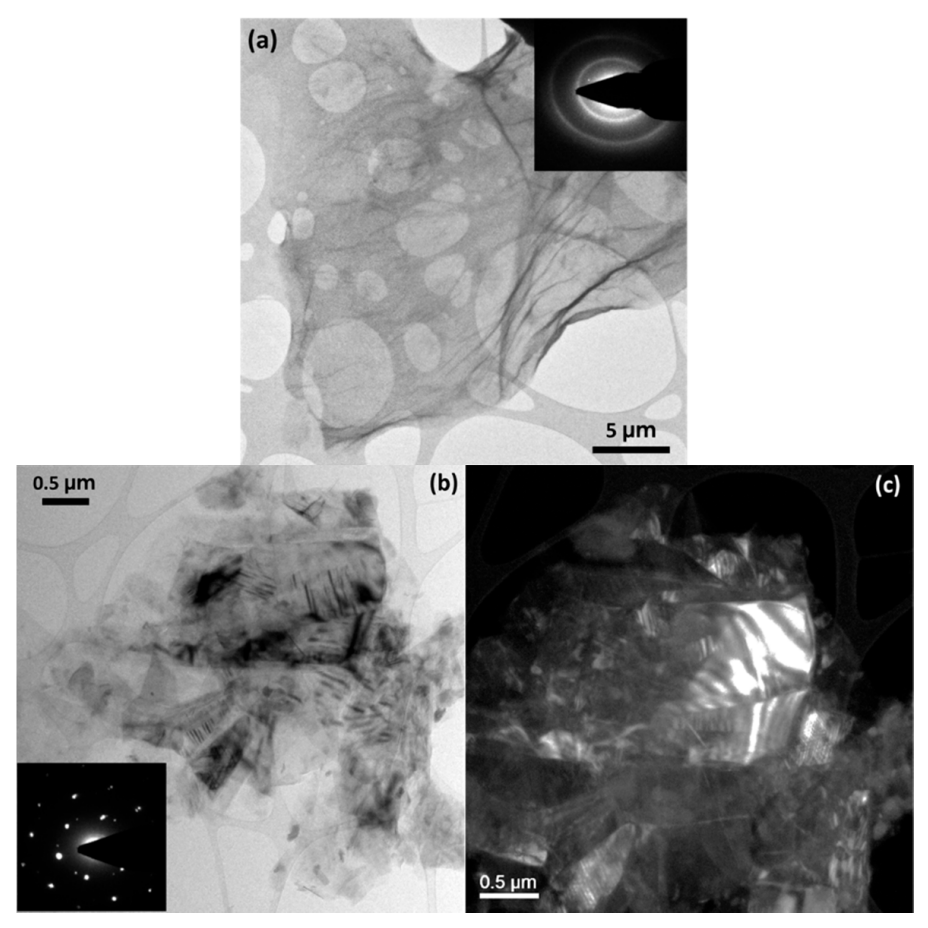

Figure 3. TEM micrographs of (a) as-produced GO with SAED pattern and (b,c) bright and dark field of $\mathrm{RGO} \mathrm{H}_{2} \mathrm{SO}_{4} 12 \mathrm{M}$ with SAED pattern.
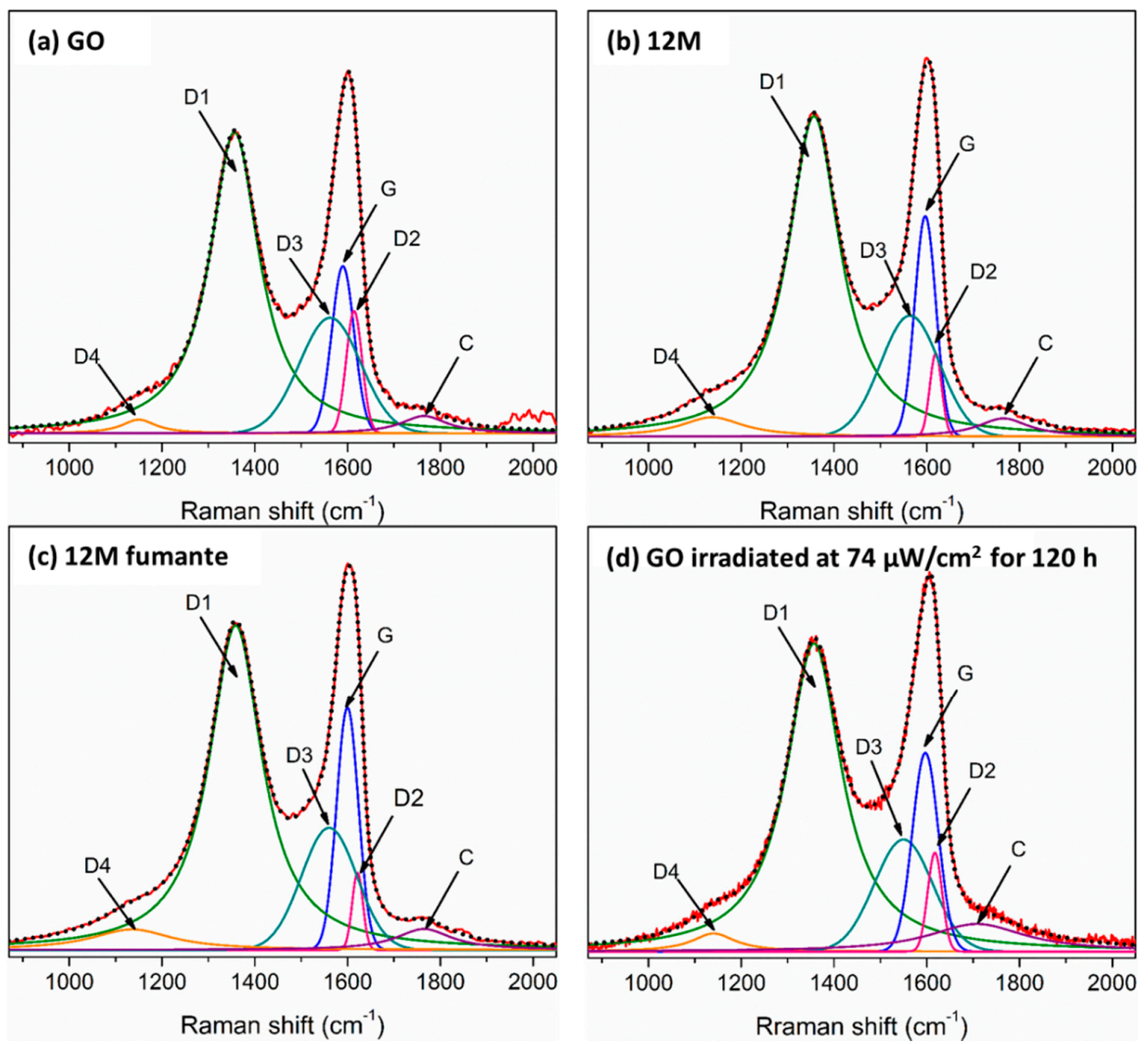

Figure 4. Raman spectroscopy spectra of (a) as-produced GO, (b) RGO treated with $\mathrm{H}_{2} \mathrm{SO}_{4}$ in $12 \mathrm{M}$ concentration, (c) RGO treated with fuming $\mathrm{H}_{2} \mathrm{SO}_{4}$ in $12 \mathrm{M}$ concentration, and (d) RGO irradiated at $74 \mu \mathrm{W} / \mathrm{cm}^{2}$ for $120 \mathrm{~h}$.

The ratio between the intensity of the $\mathrm{D}$ and $\mathrm{G}$ bands $\left(\mathrm{I}_{\mathrm{D}} / \mathrm{I}_{\mathrm{G}}\right)$ was also calculated since it is generally used to measure structural disorder. The $\mathrm{I}_{\mathrm{D}} / \mathrm{I}_{\mathrm{G}}$ ratio decreased from 
1.62 to 1.57 in $\mathrm{RGO}$ treated with $12 \mathrm{M} \mathrm{H}_{2} \mathrm{SO}_{4}$, which agrees with previous reports on RGO [8-10]. It was also reported that GO reduction leads to the formation of numerous $s p^{2}$ domains, which are smaller than the average-sized domains in graphene [8-10]. This is consistent with the formation of nanocrystalline graphite in which not only does the $D$ band appear but the $G$ band shifts toward approximately $1600 \mathrm{~cm}^{-1}$, and the $\mathrm{I}_{\mathrm{D}} / \mathrm{I}_{\mathrm{G}}$ ratio increase to almost 2 [34]. Conversely, for UV irradiated RGO, the ratio $\mathrm{I}_{\mathrm{D}} / \mathrm{I}_{\mathrm{G}}$ increased to 1.83. This increase could suggest the generation of graphitic domains and the breakage of the graphene sheets, as observed in TEM. Similarly, for RGO treated with fuming $\mathrm{H}_{2} \mathrm{SO}_{4}$ $12 \mathrm{M}$, the $\mathrm{G}$ band was located at $1599.28 \mathrm{~cm}^{-1}$ and the $\mathrm{D}$ band at $1356.04 \mathrm{~cm}^{-1}$, whereas the $\mathrm{I}_{\mathrm{D}} / \mathrm{I}_{\mathrm{G}}$ ratio decreased to 1.45 .

The changes in graphitization were also evident in the variations of the full width at half maximum (FWHM) from the G band, a measure often used as a parameter of graphitization [35]. The FWHM values of the samples produced are shown in Table S3. The FWHM of as-produced GO and RGO with $12 \mathrm{M} \mathrm{H}_{2} \mathrm{SO}_{4}$ decreased from $57.92 \mathrm{~cm}^{-1}$ to $54.12 \mathrm{~cm}^{-1}$, supporting the increase in graphitization due to the reduction induced by $\mathrm{H}_{2} \mathrm{SO}_{4}$. Furthermore, the band D2 decreases its intensity, suggesting the disappearance of 5-8-5 clusters, which are associated with this band [31].

The proposed reaction mechanism for the dehydroxylation in $\mathrm{RGO}$ by using $\mathrm{H}_{2} \mathrm{SO}_{4}$ is shown in Figure S3. It is suggested that the $-\mathrm{OH}$ is protonated by an $\mathrm{H}^{+}$from $\mathrm{H}_{2} \mathrm{SO}_{4}$ [36], which occurs due to the electrostatic interaction between the positive charge of hydrogen in $\mathrm{H}_{2} \mathrm{SO}_{4}$ and the negative charge of oxygen in the -OH functional group [11]. Once the acid yields one of its protons to the hydroxyl, a water molecule is formed in addition to $\mathrm{HSO}_{4}{ }^{-}$. Subsequently, the water molecule is also released, leaving a carbon with a positive charge that forms a double bond with the neighboring carbon. This reaction was proposed to be favorable and has an activation energy of $7.7 \mathrm{kcal} / \mathrm{mol}$ [11]. On the other hand, it was proposed that the de-epoxidation occurs by opening the epoxide ring [11,12]. Initially, oxygen is protonated, which causes the opening of the ring, resulting in the formation of a C-OH functional and a water molecule. Finally, this water molecule releases an $\mathrm{H}^{+}$, producing another -OH group (Figure S4) [11].

As previously reported, during GO oxidation, the first functional group to be generated is $-\mathrm{OH}$, and its subsequent oxidation results in the $\mathrm{C}-\mathrm{O}-\mathrm{C}, \mathrm{C}=\mathrm{O}$, and $\mathrm{COOH}$ groups [23]. The reduction process occurs similarly since, in addition to the loss of -OH groups, there is the transformation of the $\mathrm{C}-\mathrm{O}-\mathrm{C}$ group into the $-\mathrm{OH}$, which was previously described as de-epoxidation [11,12]. This explains what was observed by XPS (Table 1) in which the percentage of the $-\mathrm{OH}$ and $\mathrm{C}-\mathrm{O}-\mathrm{C}$ group decreased after the treatment with a low concentration of $\mathrm{H}_{2} \mathrm{SO}_{4}$. However, as the acid concentration increases, the percentage of the $-\mathrm{OH}$ group increases, and the percentage of $\mathrm{C}-\mathrm{O}-\mathrm{C}$ decrease significantly. On the other hand, it was also reported that the reduction of the $\mathrm{C}=\mathrm{O}$ and $\mathrm{COOH}$ groups by S-containing compounds requires high activation energy, making it easier to reduce the functional groups inside the basal plane [11].

\section{Conclusions}

The chemical reduction of $\mathrm{GO}$ by using $\mathrm{H}_{2} \mathrm{SO}_{4}$ was achieved in different degrees, depending on its concentration. The optimal concentration for the production of RGO was $12 \mathrm{M}$ since the carbon structure was reestablished through the loss of the oxygenated functional groups such as an epoxide. A reaction mechanism was proposed to illustrate the transformation of the epoxide group into the hydroxyl $(-\mathrm{OH})$ group and its subsequent elimination by a dehydration process due to the action of sulfuric acid. Furthermore, no sulfur doping was observed, a common problem in chemical reduction methods for GO with sulfur-containing compounds such as sodium hydrogen sulfite $\left(\mathrm{NaHSO}_{3}\right)$ or with nitrogen-containing compounds such as hydrazine $\left(\mathrm{N}_{2} \mathrm{H}_{4}\right)$. The use of fuming sulfuric acid also showed some improvement on the reduction of $\mathrm{GO}$ by reaching a carbon content of $74 \%$, however, XPS suggested that it also led to the contamination of RGO with $1.3 \%$ 
sulfur. Using $\mathrm{H}_{2} \mathrm{SO}_{4}$ is a promising method for reducing GO to obtain RGO since it can be applied as a single-step.

Supplementary Materials: The following are available online at https://www.mdpi.com/1996-1 944/14/1/59/s1, Figure S1. XPS narrow scan of RGO treated with $\mathrm{H}_{2} \mathrm{SO}_{4}$ at (a) $1.5 \mathrm{M}$, (b) $5 \mathrm{M}$, and (c) $12 \mathrm{M}$ and fuming $\mathrm{H}_{2} \mathrm{SO}_{4}$ at (d) $12 \mathrm{M}$. The presence of sulfur it can be observed only in the RGO treated with fuming $\mathrm{H}_{2} \mathrm{SO}_{4}$ at $12 \mathrm{M}$, due to the excess of sulfur trioxide $\left(\mathrm{SO}_{3}\right)$ in the acid, Figure S2. Raman spectroscopy spectra of $\mathrm{GO}$ treated with $\mathrm{H}_{2} \mathrm{SO}_{4}$ in (a) $1.5 \mathrm{M}$ and (b) $5 \mathrm{M}$ concentrations, Table S1. Position of bands $\mathrm{G}$ and $\mathrm{D}$ in Raman spectra and ID/IG ratio for as-produced GO; GO treated with $\mathrm{H}_{2} \mathrm{SO}_{4}$ in concentrations of $1.5,5$, and $12 \mathrm{M}$; $\mathrm{GO}$ treated with fuming $\mathrm{H}_{2} \mathrm{SO}_{4}$ in concentration of $12 \mathrm{M}$; and OG irradiated at $74 \mu \mathrm{W} / \mathrm{cm}^{2}$ for $120 \mathrm{~h}$, Table S2. Position of bands D2, D3, D4, and $\mathrm{C}$ in Raman spectra for as-produced GO; $\mathrm{GO}$ treated with $\mathrm{H}_{2} \mathrm{SO}_{4}$ in concentrations of 1.5, 5, and $12 \mathrm{M}$; GO treated with fuming $\mathrm{H}_{2} \mathrm{SO}_{4}$ in concentration of $12 \mathrm{M}$; and OG irradiated at $74 \mu \mathrm{W} / \mathrm{cm}^{2}$ for $120 \mathrm{~h}$, Table S3. Values for the FWHM of bands $\mathrm{G}$ and D in Raman spectra for as-produced GO, GO treated with $\mathrm{H}_{2} \mathrm{SO}_{4}$ in concentrations of $1.5,5$, and $12 \mathrm{M}$; $\mathrm{GO}$ treated with fuming $\mathrm{H}_{2} \mathrm{SO}_{4}$ in concentration of $12 \mathrm{M}$; and GO irradiated at $74 \mu \mathrm{W} / \mathrm{cm}^{2}$ for $120 \mathrm{~h}$, Figure S3. Reduction mechanism of $\mathrm{GO}$ by the loss of -OH functional group by the effect of $\mathrm{H}_{2} \mathrm{SO}_{4}$, Figure S4. Reduction mechanism of $\mathrm{GO}$ by the opening of C-O-C functional group (de-epoxidation) by the effect of $\mathrm{H}_{2} \mathrm{SO}_{4}$.

Author Contributions: A.C.R.-M.: Investigation, methodology, formal analysis, writing-original draft and writing-review \&editing. E.G.-C.: Formal analysis. R.V.: Formal analysis and writingreview \& editing. E.L.-H.: Project administration, resources, supervision and writing-review \& editing. All authors have read and agreed to the published version of the manuscript.

Funding: Work sponsored by a grant from Secretaría de Energía and Consejo Nacional de Ciencia y Tecnología (SENER-CONACYT) as part of the Centro Mexicano de Innovación en Energía del Océano (CEMIE-Océano) (project number 249795).

Institutional Review Board Statement: Not applicable.

Informed Consent Statement: Not applicable.

Data Availability Statement: Data is contained within the article or supplementary material.

Acknowledgments: The authors acknowledge CONACYT for the Ph.D. scholarship awarded to A. C. Reynosa-Martínez and E. Gomez-Chaires. This manuscript has been authored by UT-Battelle, LLC, under contract DE-AC05-00OR22725 with the US Department of Energy (DOE). The US government retains and the publisher, by accepting the article for publication, acknowledges that the US government retains a nonexclusive, paid-up, irrevocable, worldwide license to publish or reproduce the published form of this manuscript, or allow others to do so, for US government purposes. DOE will provide public access to these results of federally sponsored research in accordance with the DOE Public Access Plan (http:/ / energy.gov/downloads/doe-public-access-plan).

Conflicts of Interest: The authors declare no conflict of interest.

\section{References}

1. Gómez-Navarro, C.; Meyer, J.C.; Sundaram, R.S.; Chuvilin, A.; Kurasch, S.; Burghard, M.; Kern, K.; Kaiser, U. Atomic structure of reduced graphene oxide. Nano Lett. 2010, 10, 1144-1148. [CrossRef] [PubMed]

2. Zhao, M.; Reda, A.T.; Zhang, D. Reduced Graphene Oxide/ZIF-67 Aerogel Composite Material for Uranium Adsorption in Aqueous Solutions. ACS Omega 2020, 5, 8012-8022. [CrossRef] [PubMed]

3. Yao, T.; Xin, G.; Scott, S.M.; Gong, B.; Lian, J. Thermally-Conductive and Mechanically-Robust Graphene Nanoplatelet Reinforced UO2 Composite Nuclear Fuels. Sci. Rep. 2018, 8, 2-10. [CrossRef]

4. Lozada-Hidalgo, M.; Zhang, S.; Hu, S.; Esfandiar, A.; Grigorieva, I.V.; Geim, A.K. Scalable and efficient separation of hydrogen isotopes using graphene-based electrochemical pumping. Nat. Commun. 2017, 8, 15215. [CrossRef] [PubMed]

5. Mancillas-Salas, S.; Barroso-Flores, J.; Villaurrutia, R.; García-Montalvo, V.; López-Honorato, E. Production of few-layer graphene by wet media milling using organic solvents and different types of graphite. Ceram. Int. 2019, 46, 2413-2420. [CrossRef]

6. Teng, C.; Xie, D.; Wang, J.; Yang, Z.; Ren, G.; Zhu, Y. Ultrahigh Conductive Graphene Paper Based on Ball-Milling Exfoliated Graphene. Adv. Funct. Mater. 2017, 27, 1700240. [CrossRef]

7. Zhao, W.; Fang, M.; Wu, F.; Wu, H.; Wang, L.; Chen, G. Preparation of graphene by exfoliation of graphite using wet ball milling. J. Mater. Chem. 2010, 20, 5817-5819. [CrossRef]

8. Kim, D.; Yang, S.J.; Kim, Y.S.; Jung, H.; Park, C.R. Simple and cost-effective reduction of graphite oxide by sulfuric acid. Carbon N. Y. 2012, 50, 3229-3232. [CrossRef] 
9. Stankovich, S.; Dikin, D.A.; Piner, R.D.; Kohlhaas, K.A.; Kleinhammes, A.; Jia, Y.; Wu, Y.; Nguyen, S.B.T.; Ruoff, R.S. Synthesis of graphene-based nanosheets via chemical reduction of exfoliated graphite oxide. Carbon N. Y. 2007, 45, 1558-1565. [CrossRef]

10. Chen, W.; Yan, L.; Bangal, P.R. Chemical Reduction of Graphene Oxide to Graphene by Sulfur-Containing Compounds. J. Phys. Chem. C 2010, 114, 19885-19890. [CrossRef]

11. Su, Y.; Gao, X.; Zhao, J. Reaction mechanisms of graphene oxide chemical reduction by sulfur-containing compounds. Carbon N. Y. 2014, 67, 146-155. [CrossRef]

12. Pei, S.; Zhao, J.; Du, J.; Ren, W.; Cheng, H. Direct reduction of graphene oxide films into highly conductive and flexible graphene films by hydrohalic acids. Carbon N. Y. 2010, 48, 4466-4474. [CrossRef]

13. Gallegos-Pérez, W.R.; Reynosa-Martínez, A.C.; Soto-Ortiz, C.; Álvarez-Lemus, M.A.; Barroso-Flores, J.; García-Montalvo, V.; López-Honorato, E. Effect of UV radiation on the structure of graphene oxide in water and its impact on cytotoxicity and As(III) adsorption. Chemosphere 2020, 249, 126160. [CrossRef] [PubMed]

14. Tien, H.N.; Luan, V.H.; Lee, T.K.; Kong, B.-S.; Chung, J.S.; Kim, E.J. Enhanced solvothermal reduction of graphene oxide in a mixed solution of sulfuric acid and organic solvent. Chem. Eng. J. 2012, 211-212, 97-103. [CrossRef]

15. Marcano, D.C.; Kosynkin, D.V.; Berlin, J.M.; Sinitskii, A.; Sun, Z.; Slesarev, A.; Alemany, L.B.; Lu, W.; Tour, J.M. Improved synthesis of graphene oxide. ACS Nano 2010, 4, 4806-4814. [CrossRef] [PubMed]

16. Reynosa-Martínez, A.C.; Navarro-Tovar, G.; Gallegos, W.R.; Rodríguez-Melendez, H.; Torres-Cadena, R.; Mondragón-Solórzano, G.; Barroso-Flores, J.; Alvares-Lemus, M.A.; García-Montalvo, V.; López-Honorato, E. Effect of the degree of oxidation of graphene oxide on As(III) adsorption. J. Hazard. Mater. 2020, 382, 121440. [CrossRef]

17. Fairley, N. 2.3.13 Introduction to XPS and AES. In CasaXPS Manual; Casa Software Ltd.: Teignmouth, UK, $2009 ;$ pp. 1-177.

18. Perrozzi, F.; Croce, S.; Treossi, E.; Palermo, V.; Santucci, S.; Fioravanti, G.; Ottaviano, L. Reduction dependent wetting properties of graphene oxide. Carbon N. Y. 2014, 77, 473-480. [CrossRef]

19. Stankovich, S.; Piner, R.D.; Chen, X.; Wu, N.; Nguyen, S.T.; Ruoff, R.S. Stable aqueous dispersions of graphitic nanoplatelets via the reduction of exfoliated graphite oxide in the presence of poly(sodium 4-styrenesulfonate). J. Mater. Chem. 2006, 16, 155-158. [CrossRef]

20. Ganguly, A.; Sharma, S.; Papakonstantinou, P.; Hamilton, J. Probing the Thermal Deoxygenation of Graphene Oxide Using High-Resolution In Situ X-ray-Based Spectroscopies. J. Phys. Chem. 2011, 115, 17009-17019. [CrossRef]

21. Ren, P.; Yan, D.; Ji, X.; Chen, T. Temperature dependence of graphene oxide reduced by hydrazine hydrate. Nanotechnology 2011, 22, 055705. [CrossRef]

22. Smith, M.W.; Dallmeyer, I.; Johnson, T.J.; Brauer, C.S.; Mcewen, S.; Espinal, J.F.; Garcia-perez, M. Structural analysis of char by Raman spectroscopy: Improving band assignments through computational calculations from first principles. Carbon N. Y. 2016, 100, 678-692. [CrossRef]

23. Liu, Z.; Duan, X.; Zhou, X.; Qian, G.; Zhou, J.; Yuan, W. Controlling and formation mechanism of oxygen-containing groups on graphite oxide. Ind. Eng. Chem. Res. 2014, 53, 253-258. [CrossRef]

24. Ţucureanu, V.; Matei, A.; Avram, A.M. FTIR Spectroscopy for Carbon Family Study. Crit. Rev. Anal. Chem. 2016, 46, 502-520. [CrossRef] [PubMed]

25. Mkhoyan, K.A.; Contryman, A.W.; Silcox, J.; Stewart, D.A.; Eda, G.; Mattevi, C.; Miller, S.; Chhowalla, M. Atomic and electronic structure of graphene-oxide. Nano Lett. 2009, 9, 1058-1063. [CrossRef]

26. López-Honorato, E.; Meadows, P.J.; Xiao, P. Fluidized bed chemical vapor deposition of pyrolytic carbon-I. Effect of deposition conditions on microstructure. Carbon N. Y. 2009, 47, 396-410. [CrossRef]

27. Moon, I.K.; Lee, J.; Ruoff, R.S.; Lee, H. Reduced graphene oxide by chemical graphitization. Nat. Commun. 2010, 1, 73. [CrossRef]

28. Sadezky, A.; Muckenhuber, H.; Grothe, H.; Niessner, R.; Pöschl, U. Raman microspectroscopy of soot and related carbonaceous materials: Spectral analysis and structural information. Carbon N. Y. 2005, 43, 1731-1742. [CrossRef]

29. Ferrari, A.C. Raman spectroscopy of graphene and graphite: Disorder, electron-phonon coupling, doping and nonadiabatic effects. Solid State Commun. 2007, 143, 47-57. [CrossRef]

30. Sethuraman, V.A.; Hardwick, L.J.; Srinivasan, V.; Kostecki, R. Surface structural disordering in graphite upon lithium intercalation/deintercalation. J. Power Source 2010, 195, 3655-3660. [CrossRef]

31. Claramunt, S.; Varea, A.; López-Díaz, D.; Velázquez, M.M.; Cornet, A.; Cirera, A. The importance of interbands on the interpretation of the raman spectrum of graphene oxide. J. Phys. Chem. C 2015, 119, 10123-10129. [CrossRef]

32. Krishnamoorthy, K.; Veerapandian, M.; Yun, K.; Kim, S.J. The chemical and structural analysis of graphene oxide with different degrees of oxidation. Carbon N. Y. 2013, 53, 38-49. [CrossRef]

33. Schüpfer, D.B.; Badaczewski, F.; Peilst, J.; Guerra-castro, J.M.; Shim, H.; Firoozabadi, S.; Beyer, A.; Volz, K.; Presser, V.; Heiliger, C.; et al. Monitoring the thermally induced transition from sp3-hybridized into sp2-hybridized carbons. Carbon N. Y. 2020, 172, 214-227. [CrossRef]

34. Ferrari, A.C.; Robertson, J. Interpretation of Raman spectra of disordered and amorphous carbon. Phys. Rev. B 2000, 61, 95-107. [CrossRef]

35. Yoshida, A.; Kaburagi, Y.; Hishiyama, Y. Full width at half maximum intensity of the G band in the first order Raman spectrum of carbon material as a parameter for graphitization. Carbon N. Y. 2006, 44, 2333-2335. [CrossRef]

36. Shin, Y.; Jung, S.; Jeon, I.; Baek, J. The oxidation mechanism of highly ordered pyrolytic graphite in a nitric acid/sulfuric acid mixture. Carbon N. Y. 2019, 52, 493-498. [CrossRef] 